REFLEXIVE

Journal of Critical Dietetics

ISSN 1923-1237

Vol 5, Issue 2

Copyright 2021

Toronto, $\mathrm{ON}$

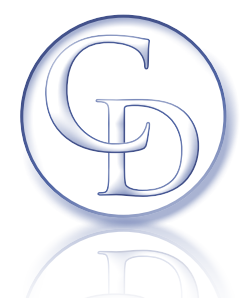

\title{
Alignment of Ethical Guidelines for Research Involving Transgender People and Communities with Critical Dietetics: A Declaration
}

By Samantha Firth, BSc (Psych), BSN and Catherine Morley, PDt, PhD, FDC, School of Nutrition and Dietetics, Acadia University

Keywords: transgender, gender diversity, nutrition assessment, nutrition care, critical dietetics, research ethics No financial support was received for this research.

Acknowledgments: Thanks to Drew Burchell and Heather Bonnell for their insights.

The authors have no conflicts of interest.

Articulating the project

My (CM) program of research is aimed at raising awareness of the food, nutrition, and eating challenges of $T+G D$ people and to develop relevant nutrition care guidelines (NCGs). The intent is that dietitians, administrators, and policy advocates will use the NCGs in advocating for/offering services that optimally support the T+GD community.

Colleagues have expressed interest in evidence-based guidance in providing nutritional care via the Critical Dietetics, and Dietitians' Support Facebook groups, and conversations following presentations at Dietitians of Canada (DC), Critical Dietetics (CD), and the CPATH conferences. In Braindate meetings' with students/recent graduates as part of DC conferences, I heard reports from some practicum students of some practicum preceptors insisting on using a person's dead name and incorrect pronoun: the students felt extremely uncomfortable and powerless to speak out. These experiences, combined with knowledge that there is little extant literature on these topics, no T+GD-specific NCGs, and that the 2019 Public Health annual report declared not addressing a person by their name and pronoun is a form of stigma and therefore, unacceptable, highlight the pressing need for professional training and resources for dietitians. In embarking on this area of research, a priority was determining guiding principles to inform the work. As a signatory to Critical Dietetics: A Declaration (Aphramor et al., 2009), I have been committed to dietetics research consistent with the Declaration. I wondered how the CPATH Ethical Guidelines for Research Involving Transgender People \& Communities (EGR; Bauer et al., 2019) aligned with the Declaration. Coincidentally, SF was interested in building on our team's research on the food, nutrition, and eating issues of T+GD people (Morley et al., 2019) for Senior Seminar (SS), the BSN capstone course at Acadia. Therefore, SF's project became a comparison of Critical Dietetics: A Declaration (Aphramor et al., 2009) and the CPATH document (Bauer et al., 2019) to note any consistencies and discrepancies.

We present the remainder of this article as a conversation.

I Braindates are one-on-one or group conversations that one books with other participants at a conference. 
CM: Having agreed on the topic for your SS project, what was your research method?

SF: First, I read the documents thoroughly to get a sense of what they contained. During the second review, I noted key ideas from each document. On the third review, I checked my notes to ensure I had all relevant points. I then organized the notes, grouping like ideas from each document side by side in a notebook for ease of visual comparison and number coded similarities. I grouped like items in a table, removing duplicates, and then identified a term or phrase that encompassed the collection of ideas (creating themes). I then conducted a literature search using the terms 'transgender nutrition', 'Critical Dietetics', and 'transgender health'. I did this after theming as I did not want to bias my analysis based on others' interpretations. I observed that findings from the literature were consistent with my theming.

CM: What is important to consider is that this kind of analysis reflects a person's ontology (what they believe is important or 'the truth' about their topic and how they came to believe that truth (Business Research Methods, n.d.a.), and on their epistemology (how they believe they can get to 'the truth' about the topic, and how they came to believe that (Business Research Methods, n.d.b.). What was/is your ontology and epistemology about the topic?

SF: My ontology was/is informed by my commitment to social justice, and pragmatism, to conduct research that will be applied in practice to enhance people's lives. I believe in equitable access to healthcare, and that research should be conducted that benefits all people. I recognize(d) that remaining silent is not how I want to promote these beliefs. I am a privileged white, cisgender, able-bodied, middle-class woman; I want to use the privilege that I was born into to help create conditions for the justice I envision as I do not believe we can live in a just world when so many people face oppression. As an LGBTQ+ woman, I am specifically interested in conducting research that will benefit LGBTQ+ people.

Regarding epistemology, through my work as a research assistant following my Bachelor of Science in Psychology, I learned about multiple ways to conduct research. This was a revelation as it contrasted what I had been taught (that controlled clinical trials are the 'best' form of research). I became committed to listening to people's stories and promoting research that would create conditions for those within marginalized groups to amplify their voices. In studying nutrition and dietetics at Acadia, I was relieved to learn that your research aligned with my interests/beliefs.

CM: This is important for any researcher...'finding friends to play with'. It can be lonely and distressing when what one has worked so hard to learn about undertaking research is minimized or dismissed.

\section{Onto your results, what were the themes?}

SF: The themes (Table I) are: I) importance of diverse perspectives; 2) challenge positivist approaches; 3) encourage community engagement; 4) strengthen emancipatory research; and 5) address power dynamics and practice reflexivity.

CM: Did you present the themes in any particular order?

SF: I used the concepts of primacy and recency (Murdock, 1962); i.e., people tend to remember what they saw first and last on a list. I wanted to ensure that what I considered the most important points were highly visible and memorable.

CM: That's a useful tip. How did the documents compare re: 'importance of diverse perspectives'?

SF: In CD: A Declaration, Aphramor and colleagues (2009) encouraged "diverse forms of expression" (para. $3)$, stating that "strength comes from diversity and debate" (para. 5). Proponents of CD aimed to broaden the perspectives through which people explore and practice dietetics. Welcoming diversity of perspectives leads to conversations around power, race, gender, size, class, etc. Transdisciplinary scholarship that informs $C D$ encourages diversity in $C D$ by welcoming different methodologies/methods.

Similarly, the EGR authors recommended that research be conducted in a way that recognizes differences between $T+G D$ people and that research should benefit subgroups in the T+GD community, e.g., those who identify as non-binary, as well as the community as a whole.

As Fergusson and colleagues (20l8) wrote, it is important to note that diversity in the $T+G D$ community can affect one's vulnerability to certain negative health outcomes including food insecurity and physical illness. Awareness, knowledge, and sensitivity to the needs of T+GD people can reduce these challenges and eliminate erasure,i.e., ignoring the needs of $T+G D$ people in the healthcare 
system (Bauer et al., 2009). While pursuing my BSN, I noticed the majority of individuals studying with me were also white, cisgender women. I recognize the need for hearing the voices of those in our field outside of this demographic so that the profession can become more socially just/supportive of ideas from those belonging to varied and often marginalized groups.

CM: What I appreciate about what you have shared is that I am reminded how complex and contradictory conducting research can be; it is not so tidy as it is often portrayed. This speaks to how carefully one needs to think about what one is studying; why am I doing it?; who benefits?; why is this project important at this time?, or does it need to be done at all? I see this as the constant need for reflection/reflexion to make thoughtful decisions that will, with the best of intentions, result in research that will benefit others. Do you see a connection with the process you used?

Table I: Alignment of concepts from CD and CPATH documents

\begin{tabular}{|c|c|c|c|}
\hline Observations: & CD: A Declaration & CPATH Guidelines & Comparing documents \\
\hline $\begin{array}{l}\text { Importance of diverse } \\
\text { perspectives }\end{array}$ & $\begin{array}{l}\text { - "Strength comes from } \\
\text { diversity and debate" } \\
\text { - Expands perspectives } \\
\text { - Facilitates conversation about } \\
\text { power, race, gender, size, etc. } \\
\text { - Honours transdisciplinary } \\
\text { scholarship }\end{array}$ & $\begin{array}{l}\text { - "Nothing about us without us": } \\
\text { - Include voices of people } \\
\text { identifying as T+GD (including } \\
\text { non-binary) with different } \\
\text { backgrounds and with } \\
\text { vulnerabilities } \\
\text { - Research should benefit } \\
\text { subgroups }\end{array}$ & $\begin{array}{l}\text { - Imperative of diverse } \\
\text { perspectives in dietetics } \\
\text { research, education, and } \\
\text { practice. } \\
\text { (Note that dietetics professionals } \\
\text { are most often white, cisgender } \\
\text { women) }\end{array}$ \\
\hline $\begin{array}{l}\text { Challenge positivist } \\
\text { approaches }\end{array}$ & $\begin{array}{l}\text { - Value of transdisciplinary } \\
\text { research approaches } \\
\text { - Value all ways of knowing (not } \\
\text { privileging as more important } \\
\text { than another) }\end{array}$ & $\begin{array}{l}\text { - Adapt research methods and } \\
\text { tools to promote inclusivity } \\
\text { - Recognize the complexity of } \\
\text { individuals in the community } \\
\text { and their unique vulnerabilities } \\
\text { - Importance of research findings } \\
\text { being comprehensible to } \\
\text { stakeholders }\end{array}$ & $\begin{array}{l}\text { - The biomedical model yields } \\
\text { important yet incomplete } \\
\text { information; encourage } \\
\text { researchers to broaden } \\
\text { methods to capture life stories } \\
\text { and experiences toward } \\
\text { emancipatory outcomes }\end{array}$ \\
\hline $\begin{array}{l}\text { Encourage community } \\
\text { engagement }\end{array}$ & $\begin{array}{l}\text { - Issues facing humanity are } \\
\text { constantly changing } \\
\text { - Recognize that all positions } \\
\text { have value }\end{array}$ & $\begin{array}{l}\text { - Recognize expertise held } \\
\text { by members of the } T+G D \\
\text { community } \\
\text { - Meaningfully engage community } \\
\text { members } \\
\text { - Provide fair compensation for } \\
\text { participation }\end{array}$ & $\begin{array}{l}\text { - Respect for/recognition of } \\
\text { participants and their expertise } \\
\text { including fair and appropriate } \\
\text { compensation } \\
\text { - Create opportunities to } \\
\text { witness/honour the expertise } \\
\text { of those with lived experience }\end{array}$ \\
\hline $\begin{array}{l}\text { Strengthen } \\
\text { emancipatory research }\end{array}$ & $\begin{array}{l}\text { - Shift from participant as } \\
\text { passive receiver of knowledge } \\
\text { toward empowerment and } \\
\text { liberation }\end{array}$ & $\begin{array}{l}\text { - Focus on conducting socially } \\
\text { just research toward } \\
\text { emancipation for communities } \\
\text { and individuals }\end{array}$ & $\begin{array}{l}\text { - Recognize the social justice } \\
\text { imperative for research. } \\
\text { Otherwise, why undertake } \\
\text { research? }\end{array}$ \\
\hline $\begin{array}{l}\text { Address power } \\
\text { dynamics and practice } \\
\text { reflexivity }\end{array}$ & $\begin{array}{l}\text { - All research reflects } \\
\text { researcher's ontology and } \\
\text { epistemology; no research is } \\
\text { truly unbiased } \\
\text { - Importance of reflection } \\
\text { and reflexion and checking } \\
\text { assumptions }\end{array}$ & $\begin{array}{l}\text { Researchers should: } \\
\text { - Use privilege to remove } \\
\text { participation barriers } \\
\text { - Reflect on biases in research } \\
\text { reports } \\
\text { - Recognize gender in all } \\
\text { research (there are no unbiased } \\
\text { perspectives) }\end{array}$ & $\begin{array}{l}\text { - Check cisnormative and other } \\
\text { assumptions } \\
\text { - Moral responsibility that } \\
\text { research, education, and } \\
\text { practice will benefit the people } \\
\text { with/on behalf of whom we } \\
\text { work }\end{array}$ \\
\hline
\end{tabular}


SF: Definitely! "Strengthen emancipatory research" stood out because identifying this led me to reflect on my belief that research done with a particular group should benefit the group, not the researcher. If you keep that reason in the back of your mind, sorting through 'why am I doing this?' becomes and remains clear.

A key principle of CD is "creating space foremancipatory... scholarship" (para. 4) and welcoming "different ways of thinking and practicing within our own profession and in collaboration with allied fields" (para. 6). By encouraging emancipatory research, proponents of CD aim to move away from the idea of participants as passive receivers of what was learned toward being active contributors and decision makers, that is, toward their empowerment and liberation. Consistent with this notion, prominent in the EGR was how to conduct appropriate and just research in T+GD communities. Thus, the basis of the EGR is centered around strengthening emancipatory research to conduct research with, not for $T+G D$ individuals and communities.

CM: The sense I have is that you are saying that research should not be the domain of an elite group rather, for everyone to contribute to what is going to make a positive difference in their lives. You mentioned being a pragmatist, and wanting research to be applied to daily life. So, when we endeavour to work in collaboration with others, to minimize power differentials, and to hear from many voices, there can be the challenge of finding common ground upon which to travel on the research journey.

SF: This is where reflexivity is important, the ability of a researcher to consistently self-reflect and assess their own influences and biases regarding their research and findings (Salzman, 2002). The EGR authors highlighted the essentiality of reflexivity. One can examine their biases about gender and reflect on their privilege and the effect this has in conducting research. This can allow researchers to ensure that they are remembering their reason(s) for doing research, and that they are contributing to emancipatory and liberating work. Similarly, Gingras and colleagues (2014) identified reflexivity as a guiding framework of CD and Aphramor and colleagues (2009) noted that proponents of CD must "embrace reflexivity" (para. 3) in practice, education and research.

CM: Community engagement was another theme you identified.
SF: Yes, this is consistent with other principles of CD about the importance of engaging the public in the "ever-changing health, social, and environmental issues facing humanity" (para. 3), and recognizing that "there are no value-free positions" (para. 3; Aphramor et al., 2009).

CM: 'No value free positions' is interesting; I interpret this to mean that everyone has one or more motives for conducting research. We circle back to ontology and epistemology; one's values inform anything that a person undertakes in the name of research or producing 'evidence'. Meaning that bias is inherent in conducting research?

SF: Most definitely! In the EGR, Bauer et al. (2019) mentioned the importance of realizing the biased nature of research (as discussed above) and similarly, how researchers cannot take a completely unbiased stance on gender. They identified cisnormativity as a common assumption that can impact T+GD individuals' experiences in healthcare settings, in addition to the increased risk of discrimination, stigma and access to culturally competent healthcare (Edmiston et al., 2016; McCann \& Brown, 2017). Recognizing that no researcher is truly unbiased can encourage reflexivity to rethink traditional ideals and promote critical research. It also links to the theme of including diverse perspectives; this would be difficult to do without engaging communities. Authors of the EGR emphasized the need to recognize the expertise held by members of the community stating that it is necessary to "meaningfully engage trans communities at all stages of the research process, where possible" (pp. 3) including in the development of the research process, data analysis, and explanation of the results, and knowledge mobilization (Bauer et al., 2019). Engagement of the community may involve offering compensation for participation or co-authorship, and findings should be disseminated by and to the community. It is crucial that they are and feel respected for their expertise.

CM: Agreed, there are many examples of researchers entering into a community to gather data, and then leave without there being any benefit to those who were studied. No wonder that after a while people bar researchers from having access. This requires our attention as dietitian- researchers.

You mentioned challenging positivist paradigms. What is positivism? 
SF: Positivism is a philosophical stance that using the scientific method is the only way to find 'the truth', and the only rational way to justify beliefs (Mill, 1873; Feigl, 2019). This research paradigm has been dominant in dietetics. In CD: A Declaration, emphasis was on incorporating perspectives from the humanities, and natural and social sciences in a transdisciplinary approach as complementary to research findings generated through positivist approaches common in biomedical research. The authors stated that they "recognize that the knowledge that enables us to understand health is socially, culturally, historically, and environmentally constructed" (para. I). Gingras and colleagues (2014) expanded on this by challenging the traditional research model of positivism, stating that "it often serves the interests of those creating the knowledge - those in power" (pp. 4). The EGR are completely consistent with this view. Examples of ways to improve research within $T+G D$ communities include revising previously validated research tools, adapting research to suit communities, and recognizing the complexity of individuals and communities. We can also include challenging cultural norms about food and eating about which cisgender nutrition professionals may not be aware.

CM: This is an important idea that has been at the core of CD, that of considering forms of power (Wartenberg, 1991), especially recognizing and working to eliminate holding power over others (Morley, 2019). Dietetics professionals, with knowledge about food and nutrition, when working with those in counselling, research, or teaching situations are in positions of having the power of knowledge (Wartenberg, 1991). We have a moral responsibility to use this power to benefit participants, clients, and students.

SF: I agree. As Aphramor and colleagues (2009) put it, "CD strives to make visible our assumptions, give voice to the unspoken, embrace reflexivity, reveal and explore power relations..." (para. 3). This should be considered when acknowledging the challenges that T+GD people have experienced particularly in healthcare settings. When working with LGBTQ+ individuals, it is particularly important for dietetics professionals to be aware of when they hold cisnormative and heteronormative biases. This intertwines with the theme of 'address power dynamics and practice reflexivity'. Because of the constant selfassessment required to practice reflexivity, this creates conditions for professionals to be constantly critical of how they address this power dynamic with everyone with whom they work. As a healthcare professional or researcher coming from a place of power, holding these biases when working with $T+G D$ individuals is extremely harmful. This is consistent with Bauer and colleagues' (2019) discussion of the significance of using one's status as a researcher to remove barriers to participation, reflect on one's biases, and to generally self-reflect in research reports.

CM: It is reassuring to learn that the documents are philosophically consistent. Let's consider any limitations to your findings.

SF: Consultation with colleagues about the emerging findings would have strengthened the analysis however, the time available for the project was one term. Another limitation is that this comparison is the work of one student researcher with supervisory support; others are welcome to contribute to the discussion.

CM: What are implications of your work?

SF: Consistent with ICDEPs (Partnership for Dietetic Education and Practice, 2020), nutrition professionals must work to create conditions to provide culturally competent and safe care. This applies also to conducting research with $T+G D$ people. I thought about the relevance of varied approaches to research, and how some dietitians may use aspects of positivist biomedical research approaches and findings to perpetuate harmful views and prejudice when working with marginalized individuals. When students learn about $C D$, they can approach their education and future practice through a critical lens.

CM: I agree. When I think back to when I was working as a dietitian in clinical care and as a novice researcher, there were times when what I felt that what I had been taught to do was counter to what I felt was the 'right' or appropriate thing. Embracing multiple ways of knowing was the 'ticket' for me; recognizing that there can be and is more than one way to do things as dietitians, that critical assessments of situations (per CT) are essential if we have any hope to offer services or to conduct research that is truly in the service of the public(s) we serve.

Any research project leads to questions that will inform future research. What were yours?

SF: Three questions arose: I) How can we continue to bring $C D$ into dietetics education, research, and practice?;

2) How can we better support underrepresented groups in dietetic research and practice?; and 3) How, if at all, can the findings from this project inform the 
development of T+GD-appropriate nutrition care guidelines?

CM: Regarding participation in research, I view it as our social responsibility, as people who have the privilege to be able to enter into the lives of others through our work, to behave with respect to what others are experiencing, and to consider the individual's situation rather than to assume that NCGs arising from statistical findings apply to every person. At the same time, we cannot ignore overarching documents and concepts that are at the foundation of our work, e.g., the Social Determinants of Health (Government of Canada, 2019), the Canadian Charter of Human Rights and Freedoms (1982), or the Public Health Agency of Canada's Addressing stigma: Toward a more inclusive health system (2019). Consider the example I gave at the outset about a dietitian who would not acknowledge a person's name and pronoun? The trust is broken. Why would a person who has had a negative experience when consulting with a dietitian trust me as a dietitian-researcher? Why would they allow me to gather information?

SF: We need to consider the mistrust that being a dietitian could engender in a person whether or not perpetrated by ourselves.

CM: I am sincerely grateful for your work as your findings mean that dietetics researchers can have confidence that the EGR are aligned with the CD Declaration. I invite anyone interested in this work to connect with me so that more voices and minds are involved in moving the research forward that will enhance the lives of $T+G D$ people.

\section{References}

Aphramor, L., Asada, Y., Atkins, J., Berenbaum, S., Brady, J., Clarke, S., Coveney, J., DeVault, M., Forster-Coull, L., Fox, A., Gingras, J., Gord, C., Koc, M., Ignagni, E., Lordly, D., MacLellan, D., Manafo, E., Morley, C., Simmons, D., ... Yarker-Edgar, K. (2009). Beyond nutritionism. Practice: Exploring Members' Practice Issues, 48, I-2.

Bauer, G.R., Hammond, R., Travers, R., Kaay, M., Hohenadel, K.M., \& Boyce, M. (2009). "I don't think this is theoretical; this is our lives": How erasure impacts health care for transgender people. Journal of the Association of Nurses in AIDS Care, 20, 348-361. https://doi.org/10.1016/j. jana.2009.07.004

Bauer, G., Devor, A., Heinz, M., Marshall, Z., Pullen Sansfaçon, A., Pyne, J. (2019). CPATH ethical guidelines for research involving transgender people \& communities. http://cpath.ca/ en/resources/
Business Research Methodology. (n.d.a). Ontology. https:// research-methodology.net/research-philosophy/ontology/

Business Research Methodology. (n.d.b). Epistemology. https://research-methodology.net/research-philosophy/ epistomology/

Edmiston, E.K., Donald, C.A., Sattler, A.R., Peebles, J.K., Ehrenfeld, J.M., \& Eckstrand, K.L. (2016). Opportunities and gaps in primary care preventative health services for transgender patients: A systematic review. Transgender Health, I(I), 216-230. https://doi.org/10.1089/ trgh.2016.0019

Feigl, H. (2019, Dec 30). Positivism. Britannica. https://www. britannica.com/topic/positivism

Fergusson, P., Greenspan, N., Maitland, L., \& Huberdeau, R. (20/8). Towards providing culturally aware nutritional care for transgender people: Key issues and considerations. Canadian Journal of Dietetic Practice and Research, 79, 74-79. https://doi.org//0.3148/cjdpr-2018-001

Gingras, J., Asada, Y., Fox, A., Coveney, J., Berenbaum, S., \& Aphramor, L. (2014). Critical dietetics: A discussion paper. Journal of Critical Dietetics, 2, 2-12.

Government of Canada (1982). The Canadian Charter of Rights and Freedoms. Department of Justice. https://www.justice. gc.ca/eng/csj-sjc/rfc-dlc/ccrf-ccdl/

Government of Canada (2019). Social determinants of health. https://www.canada.ca/en/public-health/services/healthpromotion/population-health/what-determines-health. html\#al

McCann, E. \& Brown, M. (2017). Discrimination and resilience and the needs of people who identify as transgender: A narrative review of quantitative research studies. Journal of Clinical Nursing, 26, 4080-4093. https://doi.org/l0.1/11/ jocn. 13913

Mill, J.S. (1873). The positive philosophy of Auguste Comte: Volume I. Henry Holt \& Company.

Morley, C. (2019). Critical perspectives in clinical nutrition practice. In John Coveney and Sue Booth (Eds.), Critical Dietetics and Critical Nutrition Studies. London UK: Springer Publishers.

Morley, C., Monster, S., Bonnell, H., Goodridge, L. \& Falkeisen, A. (20/9). Transgender and gender diversity nutrition, food, and eating research: Our origin story. Journal of Critical Dietetics, 4(2); 58-62.

Murdock, B.B. (1962). The serial position of free recall. Journal of Experimental Psychology, 64(5), 482-488.

Partnership for Dietetic Education and Practice. (2020). Integrated competencies for dietetic education and practice (ICDEPs). https://www.pdep.ca/tools/standards.aspx 
Public Health Agency of Canada. (2019). Addressing stigma: Toward a more inclusive health system. Government of Canada. https://www.canada.ca/en/public-health/ corporate/publications/chief-public-health-officerreports-state-public-health-canada/addressing-stigmatoward-more-inclusive-health-system.html\#a4

Salzman, P.C. (2002). On reflexivity. American Anthropologist, 104(3), 805-813.

Wartenberg, T. (|99|). Forms of power: From domination to transformation. Philadelphia, PA: Temple University Press.

\section{Author bios}

Samantha Firth is a dietetic intern with Nova Scotia Health Central Zone and a recent grad-uate from Acadia University's School of Nutrition and Dietetics. Prior to beginning her degree in nutrition, Samantha completed a Bachelor of Science in Psychology at Acadia University and worked as a research assistant at Dalhousie University. Samantha became interested in Critical Dietetics after attending the Critical Dietetics Conference in 2019. In-spired and excited by what she had heard at the conference, she began the process of start-ing a Critical Dietetics Student Chapter at Acadia. Samantha has a wide range of research interests, including LGBTQ+ health and nutrition, food insecurity, and plant based nutri-tion.

(Cath)erine Morley is Acting Director and Associate Professor, School of Nutrition and Dietetics, Acadia University, Wolfville NS and Adjunct Professor, Applied Human Nutrition, Mount St. Vincent University, Halifax NS. Prior to joining Acadia University, she worked for over 20 years in cancer care, then as a consultant in nutrition program development and evaluation. Catherine's research interests are in how the experiences of eating and family relationships related to food/eating change with illness and aging, what these experiences mean for approaches to nutrition counselling, innovations in dietetics education, practice, and research including the integration of critical social theory, art-based approaches, and transinclusivity/gender diversity. 